\title{
MICROSTRUCTURE AND STABILITY COMPARISON OF NANOMETER PERIOD W/C, WC/C, AND Ru/C MULTILAYER STRUCTURES
}

\author{
Tai D. Nguyen $1,2,3$, Ronald Gronsky 2,3 , and Jeffrey B. Kortright 1 \\ ${ }^{1}$ Center for X-Ray Optics, Accelerator and Fusion Research Division, \\ 2 National Center for Electron Microscopy, \\ Materials and Chemical Sciences Division, \\ Lawrence Berkeley Laboratory, \\ ${ }^{3}$ Department of Materials Science and Mineral Engineering, \\ University of California, Berkeley, CA. 94720.
}

This work was supported by the Director, Office of Energy Research, Office of Basic Sciences, Materials Sciences Division, of the U.S. Department of Energy under Contract No. DE-AC03-76SF00098 and by the Air Force Office of Scientific Research, of the U.S. Department of Defense under Contract No. F49620-87-K-0001.

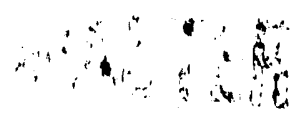




\title{
MICROSTRUCTURE AND STABILITY COMPARISON OF NANOMETER PERIOD W/C, WC/C, AND Ru/C MULTILAYER STRUCTURES
}

\begin{abstract}
:
Multilayer structures of $\mathrm{W} / \mathrm{C}, \mathrm{WC} / \mathrm{C}$, and $\mathrm{Ru} / \mathrm{C}$, of various periods were prepared and studied by high-resolution transmission electron microscopy. Comparison of the phases in the layered structures is made for as-prepared and annealed samples. Both as-prepared and annealed $\mathrm{WC} / \mathrm{C}$ multilayers are predominantly amorphous, while the phases in the $\mathrm{W} / \mathrm{C}$ depend on the periods. The 2 $\mathrm{nm}$ period $\mathrm{W} / \mathrm{C}$ multilayer remains amorphous after annealing, and the longer perinds recrystallize to form $\mathrm{W}_{2} \mathrm{C}$. The layered microstructures of $\mathrm{W} / \mathrm{C}$ and $\mathrm{WC} / \mathrm{C}$ are stable on annealing at all periods, while the amorphous $\mathrm{Ru}$-rich layers in the $2 \mathrm{~nm}$ period $\mathrm{Ru} / \mathrm{C}$ multilayer agglomerate tipon annealing to form elemental hexagonal $\mathrm{Ru}$ crystallites. Larger period $\mathrm{Ru} / \mathrm{C}$ multilayers show stable layered structures, and indicate hexagonal $\mathrm{Ru}$ in the Ru-rich layers. $\mathrm{X}$-ray measurements show that the multilayer periods expand on annealing for all metal-carbon multilayers studied.
\end{abstract}

\section{INTRODUCTION:}

Certain nanometer period multilayer structures of alternating high and low atomic number materials have proved to be effective dispersing elements at wavelengths ranging from extreme-ultraviolet to $x$-ray regions. Uniformity of the layers and sharpness of their interfaces in these multilayers are often thought as the criteria for high performance. Microstructures and phases present in the layers, however, may also have effects on the multilayer quality. Stability of the layered structures, and transformation of the phases in the layers, are also of importance in applications. Systematic studies of these layered microstructures, their phases, and their stability on annealing, lead to more complete understanding of these systems which may aid in the design of better multilayer $x$-ray interference coatings. 
Multilayers having tungsten and carbon as the primary constituents of the individual alternating layers were some of the first to demonstrate utility in $x$-ray optical applications [1,2]. Many techniques have been applied to characterize this system. X-ray scattering [3,4] and EXAFS [5] give information about the interatomic structure within the layers, and transmission electron microscopy [6-11] reveals the the quality of the layering and the nature of the phases within the layers. Previous annealing studies on the tungsten-carbon system have shown that for short periods the W-rich layers are amorphous while for longer periods they are partly crystalline, and that moderate annealing of these structures may lead to crystallization of thes 2 layers together with expansion of the multilayer periods [11].

In this paper, we compare the phases present and their stability on annealing in $\mathrm{W} / \mathrm{C}, \mathrm{WC} / \mathrm{C}$, and $\mathrm{Ru} / \mathrm{C}$ multilayers of various periods. Cross-sectional TEM studies are complemented by plan-view studies which provide more conclusive phasc identification from observation of larger areas.

\section{EXPERIMENTAL TECHNIQUES:}

Multilayers were prepared by magnetron sputtering at floating substrate temperature at the Center for X-Ray Optics. Details of the deposition conditions are described elsewhere [11]. A WC alloy target was used in DC sputtering of the WC/C multilayers. Three different nominal periods of 2, 7, and $12 \mathrm{~nm}$, were prepared for studies of the $\mathrm{W} / \mathrm{C}$ and the $\mathrm{WC} / \mathrm{C}$ multilayers. For the $\mathrm{Ru} / \mathrm{C}$ system, multilayers of 2,5 and $10 \mathrm{~nm}$ periods, were studied.

Two different characterization methods were used for this study: crosssectional and plan-view transmission electron microscopy. For cross-sectional studies, multilayers of total thickness of approximately $300 \mathrm{~nm}$ were prepared onto standard Si(111) wafers. For plan-view studies, a few bilayers of the multilayers were prepared spanning the holes of the TEM copper grids [12]. One sample from each of the cross-sectional and plan-view multilayers was annealed at $500^{\circ} \mathrm{C}$ for 4 hours in vacuum of $10^{-6}$ torr. Specimens of the as-prepared and annealed samples of the Si-substrate multilayers were prepared for cross-sectional TEM observation by mechanical thinning, and ion beam milling in cold stage at $5 \mathrm{kV}$ [13]. They were then studied in a JEOL JEM $200 \mathrm{CX}$ equipped with high resolution goniometer, opcrating at $200 \mathrm{kV}$, with the electron beam parallel to [110] of the Si substrate. The plan-view samples were studied in a Philips 301 operating at $100 \mathrm{kV}$. 
Low-angle $x$-ray reflectance measurements of the first several multilayer Bragg peaks were performed using a double-crystal $\mathrm{Cu} \mathrm{K}_{\alpha 1}$ radiation Bragg geometry to determine the periodicity of the multilayers.

\section{RESULTS AND DISCUSSIONS:}

W/C system:

Characteristic phases of the W-rich layers of the as-prepared and annealed W/C multilaycrs are summarized by the plan-view electron diffaction patterns of various period shown in figure 1. The as-prepared multilayers have predominantly amorphous microstructures at short periods. From high-resolution electron microscopy bright field images, the carbon layers in all multilayers are observed to be amorphous. The results from the $7 \mathrm{~nm}$ period indicate some micro-crystallinity present in the W-rich layers along with an anorphous phase. The sharp rings in the elcction difraction pattern of the $12 \mathrm{~nm}$ period sample indicate the dominant presence of elemental BCC tungsten in the W-rich layers, though there may be a small fraction of an amorphous phase mixed in this crystalline phase.

The layered microstructures of all periods studied remain intact after annealing. The $\mathrm{W}$-rich layers in the $2 \mathrm{~nm}$ period sample remain amorphous while those of longer period structures crystallize on annealing. Plan-view diffraction patterns presented here provide much more information than cross-sectional highresolution patterns. The ring patterns of the annealed $12 \mathrm{~nm}$ period were consistent with the identification of $\mathrm{W}_{2} \mathrm{C}$, and not of $\mathrm{WC}$, as we have reported earlier [11]. These rings also suggest that there is no preferred orientation of the crystallites in the plane of the layers. The smallest rings present in both the annealed $7 \mathrm{~nm}$ and $12 \mathrm{~nm}$ diffraction patterns, showing large spacings of approximately $3.81 \AA$, could not be identified with a carbide phase but may result form the presence of crystalline oxide or metastable carbide phases.

\section{WC/C system:}

The W.C phise diagram [14] shows low temperature carbide phases, $\mathrm{W}_{2} \mathrm{C}$ and WC. Thus significant intermixing of $W$ and $C$ in $W / C$ multilayers, as observed by various workers $[3,5,11]$, in both as-prepared and annealed samples is not surprising. 
This motivated our investigation of WC/C multilayers, since in equilibrium, WC and $\mathrm{C}$ are immiscible.

Figure 2 shows the high-resolution cross-sectional TEM images of as-prepared and annealed $2 \mathrm{~nm}$ period WC/C multilayers. The layered microstructures are stable after annealing, and show amorphous characteristics, similar to the W/C multilayers of the same period. For longer periods, the microstructures are also amorphous for both as-prepared and annealed samples, even at $12 \mathrm{~nm}$ period, as can be seen in figure 3. The amorphous structure was further confirmed by the observation of larger areas in the plan-view samples, and the diffuse rings in the corresponding electron diffraction patterns.

The results of the comparison of the microstructures and phases of the W/C and the WC/C multilayers, are summarized in Table 1. For buth systems, the laycred microstructures are stable upon annealing, even at short period. Both as-prepared and annealed multilayers of short period are predominantly amorphous. Longer periods of the WC/C system remain amorphous upon annealing, while the W-rich layers in the $\mathrm{W} / \mathrm{C}$ multilayers recrystallize to form a $\mathrm{W}_{2} \mathrm{C}$ phase. This can be explained by the high initial $C$ content in the W-rich layers of the WC/C system which stabilizes the amorphous structure against crystallization compared to the W/C system.

X-ray measuments of the low-angle Bragg peaks of the WC/C multilayers reveal the expansion of the multilayer periods upon annealing, as observed in the W/C system in various studies $[3-7,11]$.

\section{$\underline{R u / C}$ system:}

$\mathrm{Ru} / \mathrm{C}$ multilayers were studied because of their potential applications as normal incidence reflectors at soft $x$-ray wavelengths between 4.5 and $12.5 \mathrm{~nm}$. The Ru-C system is of simple eutectic type, with $\mathrm{Ru}$ and $\mathrm{C}$ immiscible with low mutual solubilities at low temperature. A RuC phase has been reported, but was not reconfirmed by other groups [15], so no equilibrium carbide phase is recorded in the solid state region.

A summary of the structural characteristics of the $\mathrm{Ru} / \mathrm{C}$ multilayers is aiso presented in Table 1. The crystalline phases were identified by the electron diffraction patterns of both cross-sectional and plan-view samples. Figure 4 shows the cross-sectional TEM irnages of the as-prepared and annealed $2 \mathrm{~nm}$ period $\mathrm{Ru} / \mathrm{C}$ multilayers. Figure $4 \mathrm{a}$ shows that the as-prepared layered microstructures are 
amorphous or have very fine micro-crystallites in the Ru-rich layers, as also evidenced by the lack of any indication of crystallinity in the corresponding diffraction pattern. Upon annealing, the $\mathrm{Ru}$ has agglomerated to form almostspherical crystallites of about $4 \mathrm{~nm}$, as seen in figure $4 \mathrm{~b}$. The layered structures are destroyed, in constrast to the $\mathrm{W} / \mathrm{C}$ and $\mathrm{WC} / \mathrm{C}$ multilayers at same period. From its diffraction pattern, the crystalline phase was identified as elemental hexagonal Ru.

For longer periods, both as-prepared and annealed samples have stable layered microstructures. Shown in figure 5 are the TEM images of the $10 \mathrm{~nm}$ period multilayers. The Ru-rich layers at thinner regions of the samples snow crossfringes of the crystalline phase. Plan-view studies of the corresponding period reveal the size of the crystallites in the as-prepared sample are in the order of few nanometers. Upon annealing, these crystallites have grown to sizes of tens of nanometers in lateral direction, which are of the same order as the Ru-rich layer thickness in the multilayer. The electron diffraction patterns of the plan-view samples indicate no signs of preferred orientation in the plane of the layers, while diffraction patterns of the elemental $\mathrm{Ru}$ in the cross-sectional samples show a strong texture in [101] perpendicular to the layer interfaces. Bright field images of the asprepared $5 \mathrm{~nm}$ period show a crystalline phase in the Ru-rich layers, although exact structures could not be identified. Its electron diffraction pattern shows diffuse rings having six-fold symmetry, which may indicate that the layers contains very small crystallites of hexagonal structures. The $2 \mathrm{~nm}$ period sample agglomerates on annealing while the 5 and $10 \mathrm{~nm}$ period samples remain layered. Since the $2 \mathrm{~nm}$ period sample has a larger interface to volume ratio than the other samples, we suggest that agglomeration of the $R u$ results from the driving force to lower interface to volume energies, which is strongest in this sample. We can not, however, rule out kinetic factors, which may also vary with period.

$\mathrm{X}$-ray measurements of the $\mathrm{Ru} / \mathrm{C}$ multilayers also indicate the expansion of the multilayer period on annealing, similar to that observed in the $W / C$ and $W C / C$ systems. The mechanism for this expansion on annealing is not well understood, though expansion appears to be linked to the amorphous C-rich layers. 


\section{SUMMARY:}

We have compared the microstructures and the phases present, and their stability upon annealing at $500^{\circ} \mathrm{C}$ for 4 hours, of $W / C, W C / C$, and $\mathrm{Ru} / \mathrm{C}$ multilayers of different periods. It was found that the phase stability of the WC/C system is very different from that of the W/C system. The as-prepared WC/C multilayers are predominantly amorphous, and remain amorphous after annealing, at all periods. The short period W/C multilayer remains amorphous upon annealing, while the longer periods recrystallize to form $\mathrm{W}_{2} \mathrm{C}$ in the $\mathrm{W}$-rich layers. For both systerns, the layered structures are stable for annealing at $500^{\circ} \mathrm{C}$ for 4 hours, even at short period. The layered microstructures of the $\mathrm{Ru} / \mathrm{C}$ multilayers, however, are stable only for longer periods, while shorter period structures agglomerate upon annealing. The phases in the as-prepared Ru-rich layers depend on the periods, namely amorphous to crystalline as the period increases. Annealing of the $\mathrm{Ru} / \mathrm{C}$ multilayers leads to formation of elemental $\mathrm{Ru}$. No carbide phases were found, consistent with the Ru-C equilibrium phase diagram.

It was observed that the periods of the multilayers expand moderately for all metal/carbon systems studied. 


\section{REFERENCES:}

1. T.W. Barbee, Jr., in Low Energy X-ray Diagnostics-1981, edited by D.T. Attwood and B.L.

Henke (AIP Conf. Proc. 75, AIP New York, 1981), p. 131.

2. E. Spiller, in Low Energy X-ray Diagnostics--1981, p. 124.

3. J.B. Kortright and J.D. Denlinger, in Multilayeis: Synthesis. Properties and NonElectronic

Applications, edited by T.W. Barbee, Jr., F. Spaepen, and L. Greer (Mater. Res. Soc. Proc. 103, Pittsburgh, PA 1988) p. 95.

4. Y. Takagi, S.A. Flessa, K.L. Hart, D.A. Pawlik, A.M. Kadin, J.L. Wood, J.E. Kecm, and

J.E. Tyler, in Applications of Thin-Film Multilayers Structures te Figured X-ray Optics, edited by G.F. Marshall (Proc. SPIE 563, Bellingham, WA 1985), p. 66.

5. G.M. Lamble, S.M. Heald, D.E. Sayers, E. Ziegler, and P.J. Viccaro, J. Appl. Phys. 65, 4250 (1989).

6. E. Ziegler, Y. Lepetre, I.K. Schuller, and E. Spiller, Apl. Phys, Let. 48, 1354 (1986).

7. Y. Lepetre, E. Ziegler, I.K. Schuller, and R. Rivoira, J. Appl. Phys. 64, 2301 (1986).

8. A.K. Petford-Long, M.B. Stearns, C.-H. Chang, S.R. Nutt, D.G. Stearns, N.M. Ceglio, and A.M. Hawryluk, J. Appl. Phys. 61, 1422 (1987).

9. S.R. Nutt and J.E. Keem, in Multilayers: Synthesis, Properties and Non-Electronic Applications, p. 87.

10. K. Holloway, K.B. Do, and R. Sinclair, in Multilayers: Synthesis. Properties and Non-Electronic Applications, p. 167.

11. T.D. Nguyen, R. Gronsky, and J.B. Kortright, in High-Resolution Microscopy of Materials, edited by W. Krakow, F.A. Ponce, and D.J. Smith (Mater. Res. Soc. Proc. 139, Pittburgh, PA 1989) p. 357.

12. T.D. Nguyen, R. Gronsky, and J.B. Kortright, in Elec. Micros. Soc. Amer, Proc., edited by G.W. Bailey (San Francisco, CA 1989) p. 680.

13. T.D. Nguyen, R. Gronsky, and J.B. Kortright (submitted to J. Elec. Microsc. Tech.). 14. W.G. Moffatt, The Handboek of Binary Phase Diagrams, vol. 2 (Genium Pub. Corp., New York 1987).

15. R.A. Shunk, Constitution of Binary Alloys. Second Supplement (McGraw-Hill Book Comp., 1969) p. 155. 


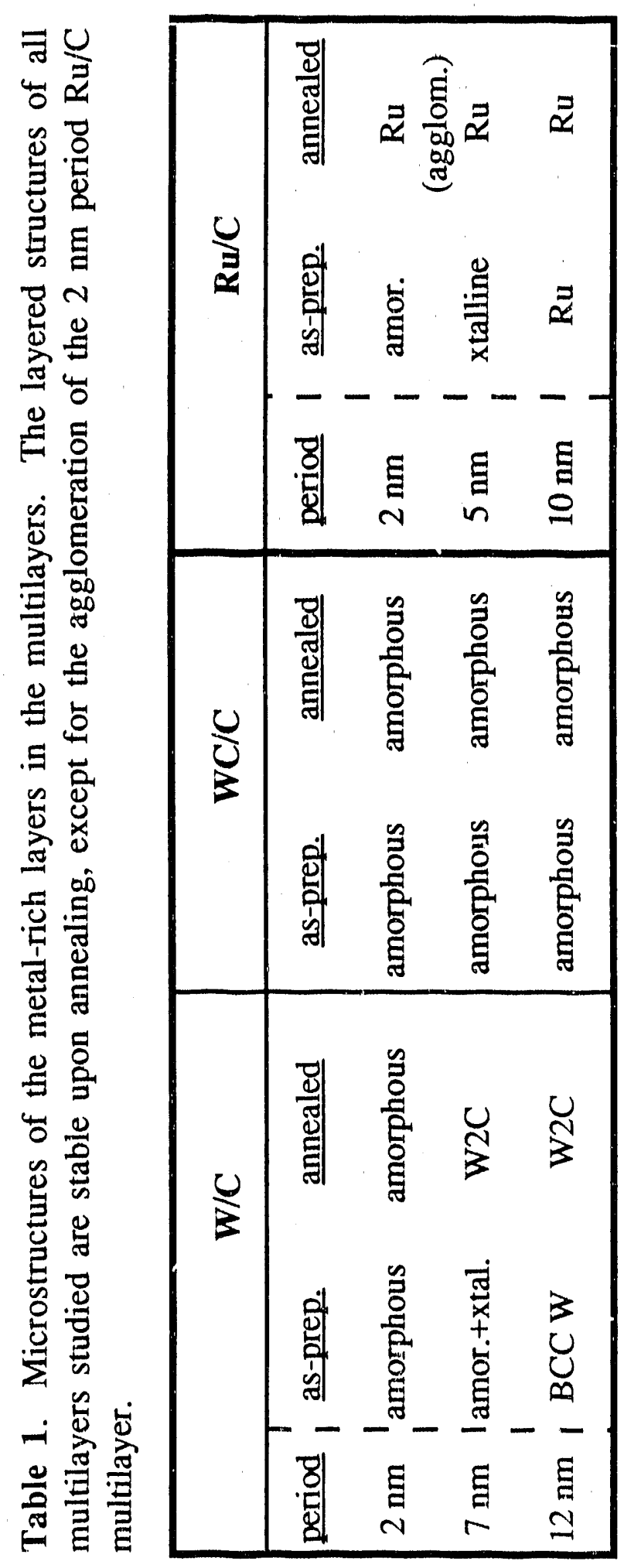



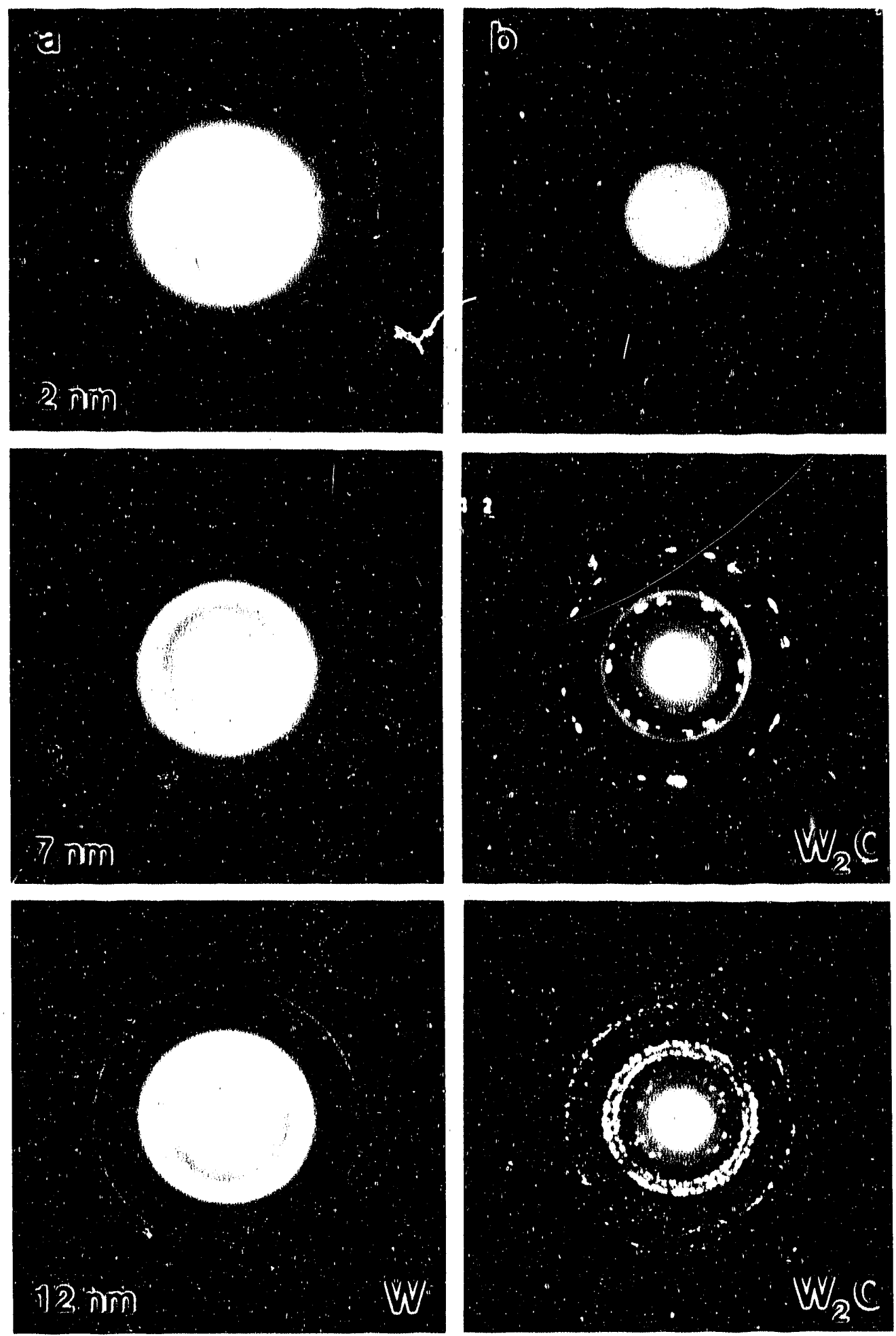

XBB $9(14-2986$

Fig. 1 -. Selected area clectron diffraction palterns of plan-view $W / C$ multilayers of 2,7 , and $12 \mathrm{~nm}$ period: a) as-prepared, b) annealed at $500^{\circ} \mathrm{C}$ for 4 hours. The ring patterns were identified with elemental $W$ for $12 \mathrm{~mm}$ asprepared, and $\mathrm{W}_{2} \mathrm{C}$ for 7 and $12 \mathrm{~nm}$ period annealed samples. 


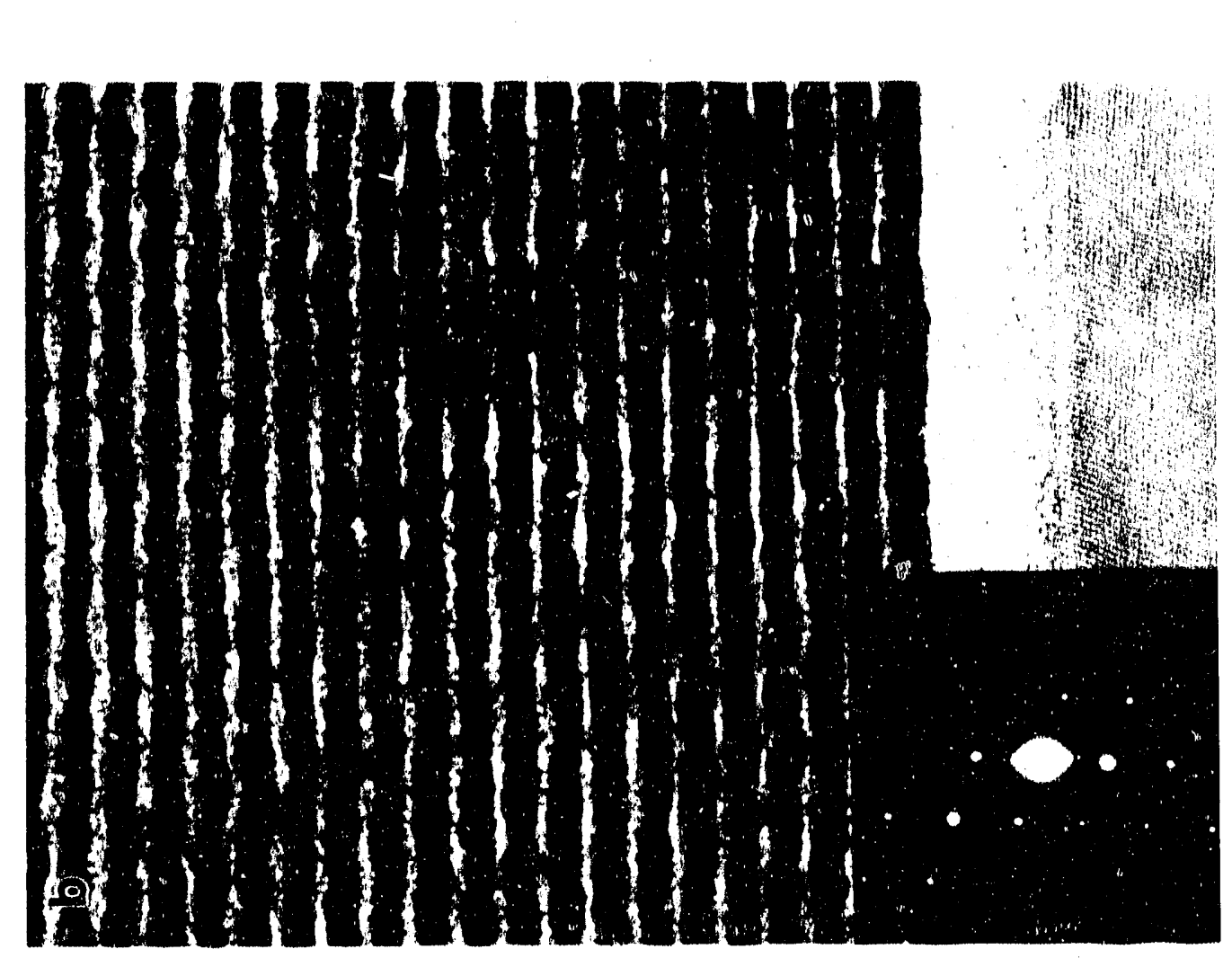

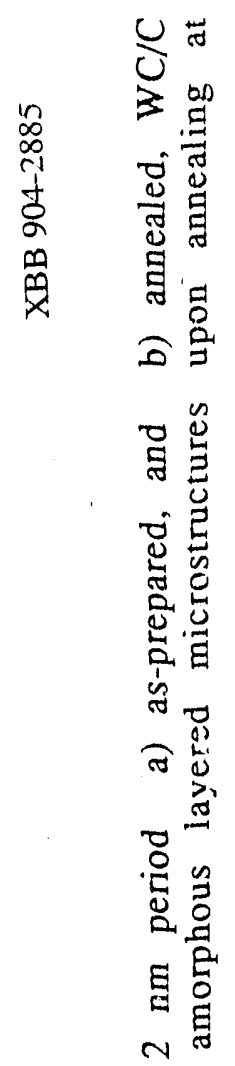
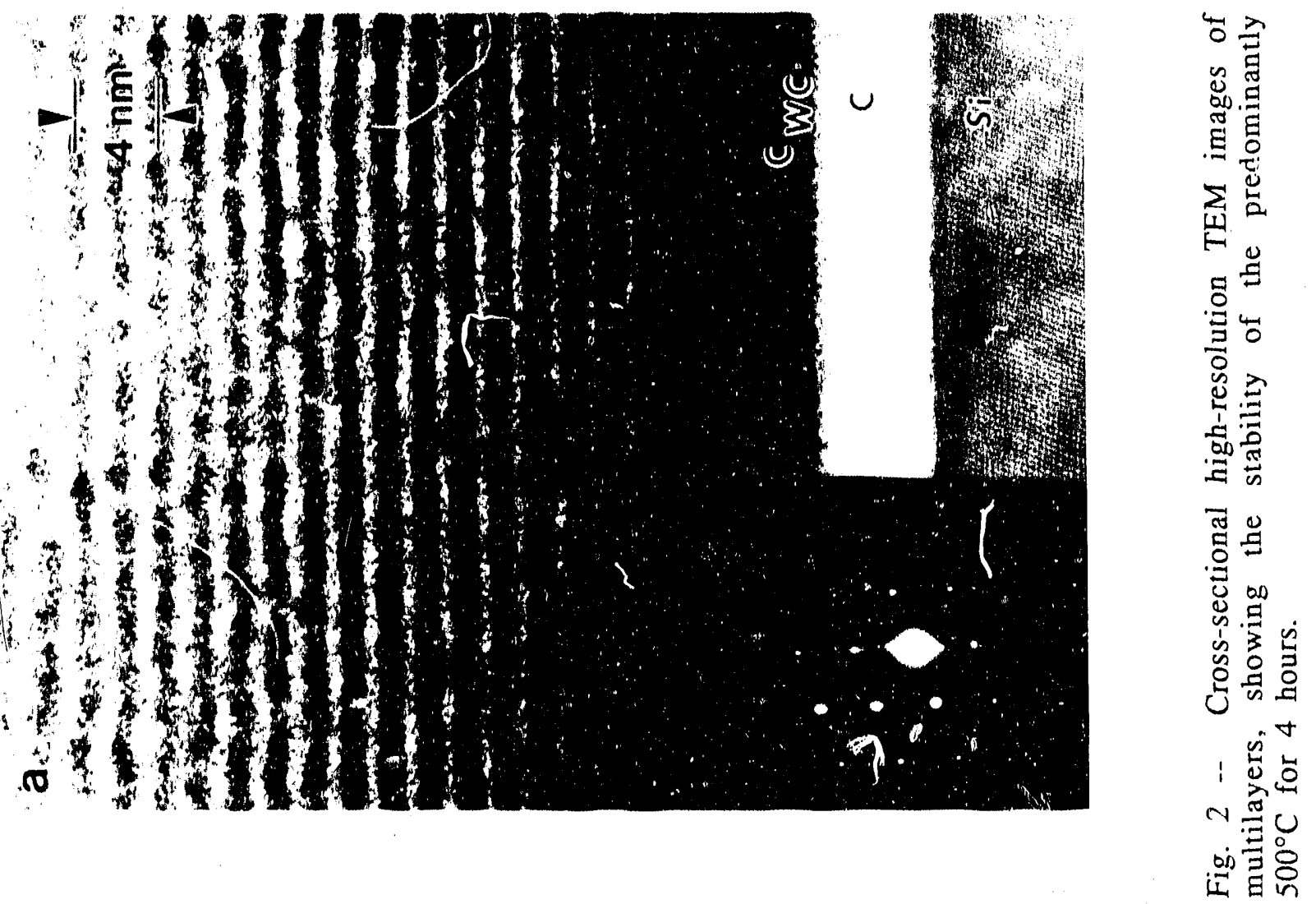


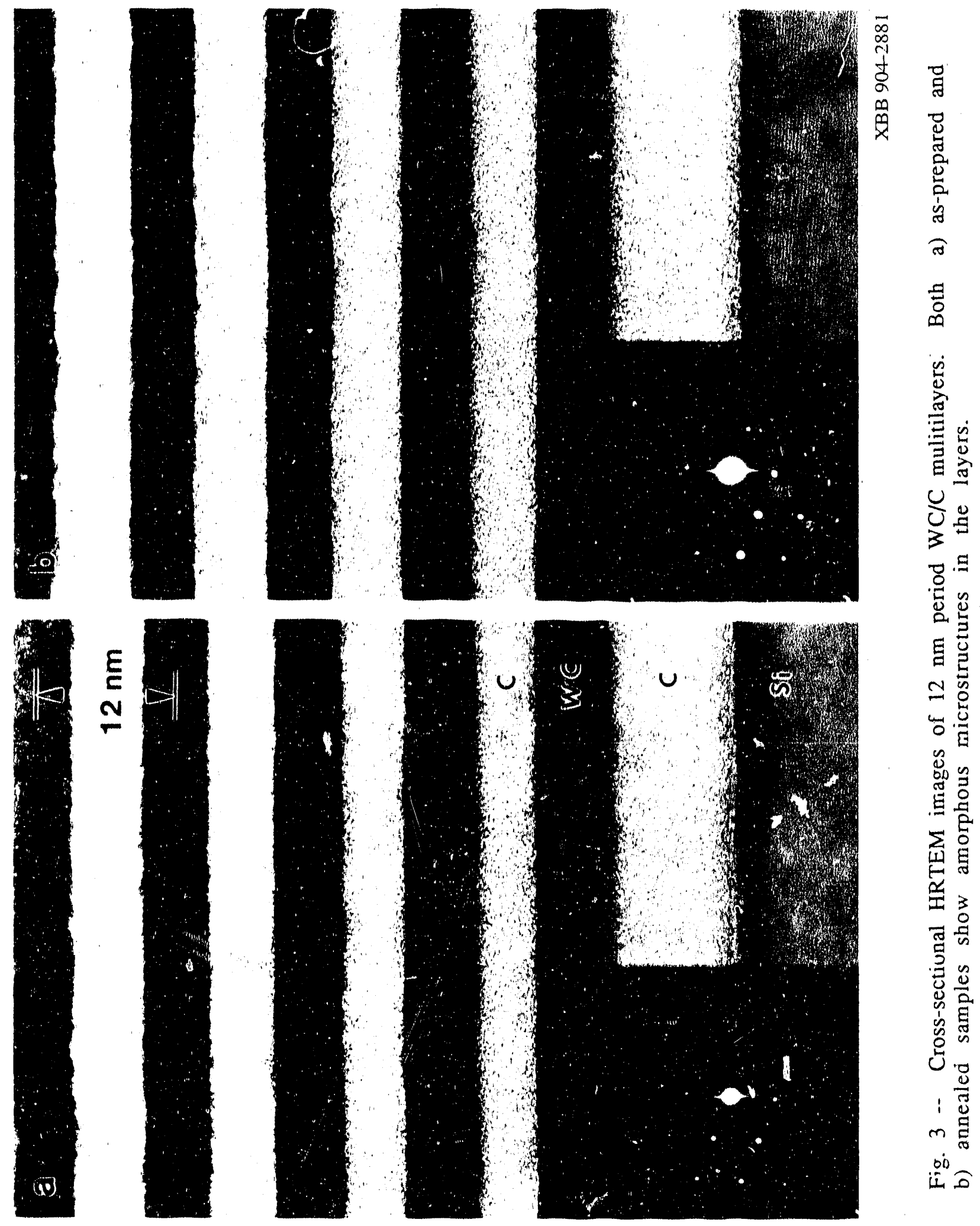



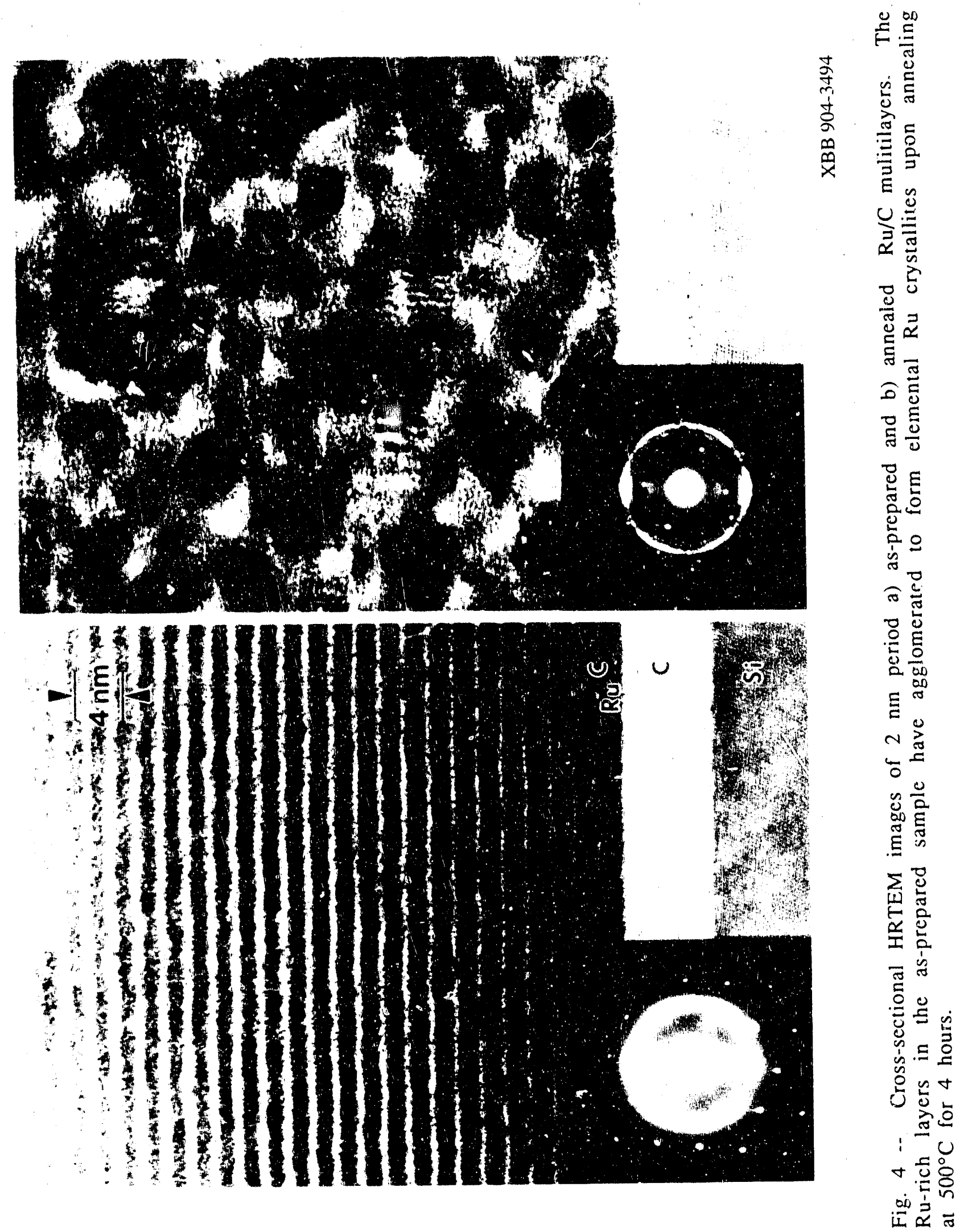


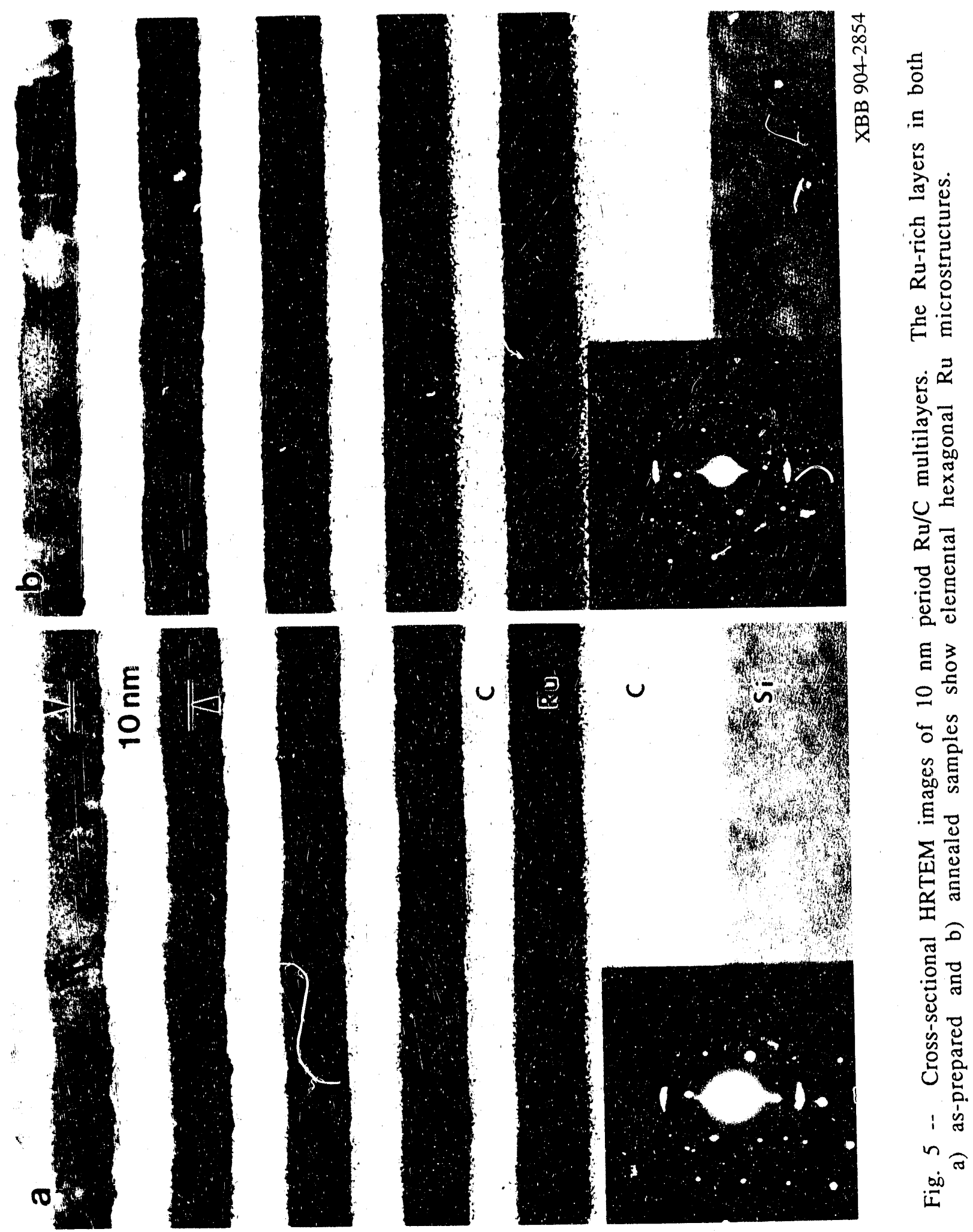



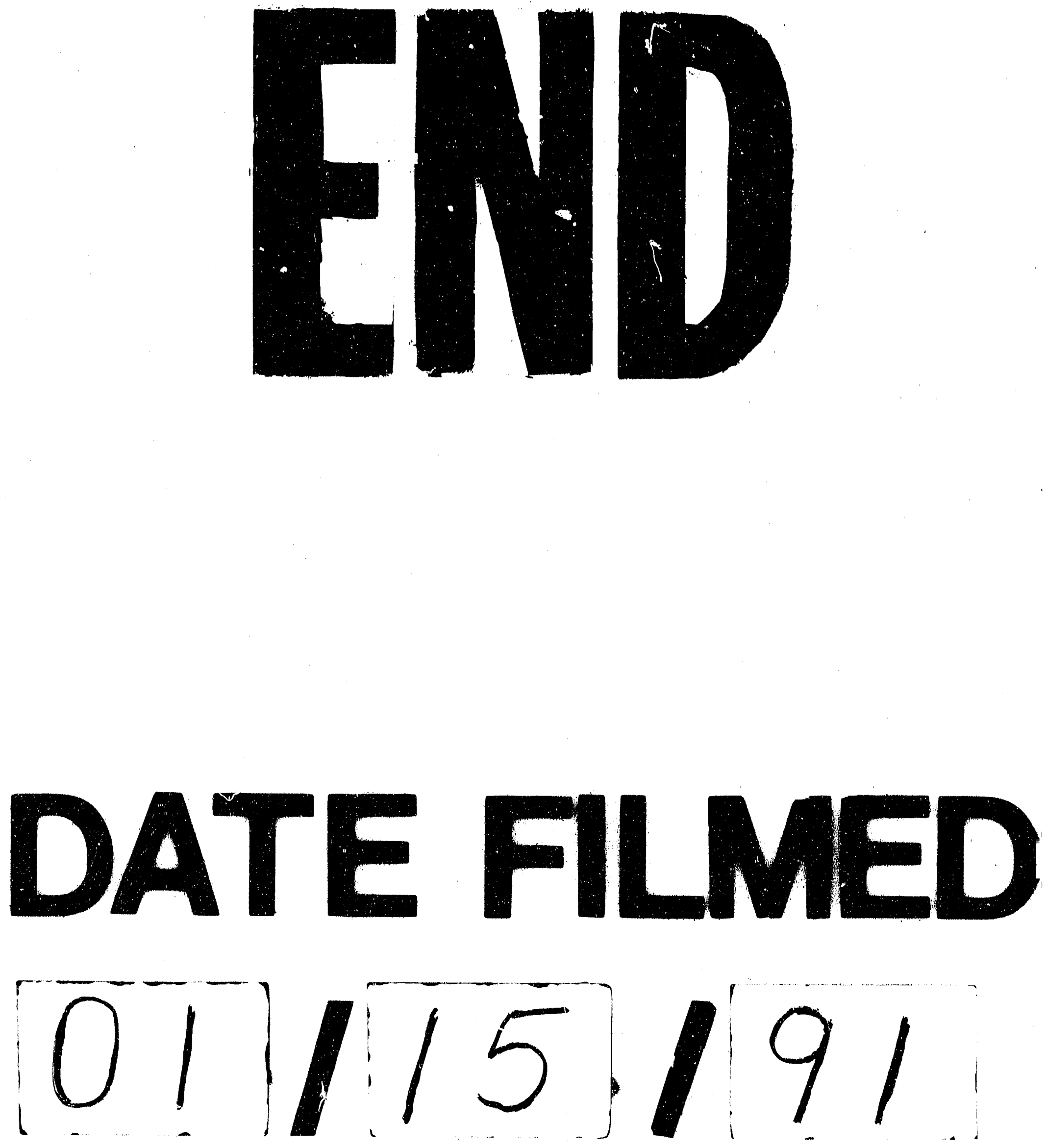
